\title{
A Short Introduction to English Poetry
}

\section{Saeed Farzane Fard}

Islamic Azad University, Sarab Branch, Department of Persian Language and Literature, Sarab, Iran

\begin{abstract}
Reading poetry is an art of discovering. Active readers ask questions about the use of words and clarify the intended use of language. They stop to summarize and to paraphrase the poem's meaning. Finally, they pull together all the elements of the poem and add to it themselves. This paper tries to gove an overview of poetry and its elements.
\end{abstract}

Keywords: Poetry, Imagery, Sonnet, Figurative Language, Musical Devices

\section{INTRODUCTION}

When we talk about understanding poetry, we must always bear in mind the essential two-fold approach to the reading of poetry: we must understand both the literal sense of the poem as well as the symbolic or suggested meaning of the poem. The poet reveals an extraordinary sensitivity to the diction of his poetry. She selects words that best express both what he feels or thinks and what he wishes his reader's response to be. We should understand at the outset that poetry can be written for different reasons and therefore each poem has a different purpose. To become appreciative readers of poetry, it is necessary that we analyze poetry on both literal and symbolic levels. If we make no effort to understand poetry in various ways, we cannot consider ourselves good readers. As Ben Jonson advised his readers in an epigram:

"Pray thee, take care, that tak'st my book in hand, to read it well: that is, to understand."

As readers like Ralph Waldo Emerson and T.S. Eliot have repeatedly remarked, we arrive at a greater understanding of people and of our society by arriving at an understanding of poetry; then is indeed a direct link between "The literature we read and the life we lead."

When we analyze poetry we begin the process by separating a poem into its component parts. This accomplished, we try to examine each of the parts first separately, then in relationship to each other, and finally, in relationship to the whole. For in poetry, the elements forming the whole have a great dependency on each other; sometimes, once we have taken a poem apart, we would automatically understand the central image and then we understand quickly all of the other parts. Analysis, in other words, is a process of intellectual dissection of a whole into its ingredients in order to understand and appreciate the integrity and message of the whole- the poem.

Sometimes the best place to begin one's analysis of a poem is with the title. In Emily Dickinson's poem, "There is no Frigate like a Book," we should thus ponder the title and ask what makes the title or the very first line meaningful:

There is no Frigate Like A Book

There is no frigate like a book

To take us lands away,

Nor any coursers like a pages

Of prancing poetry:

This traverse may the poorest take

Without oppress of toll;

How frugal is the chariot

That bears the human soul! 
The poem is short and to the point. We have been able to arrive at an understanding of both meaning and composition merely by pondering the title in relation to the poem. We find Emily Dickinson clever with her diction when she makes use of such words as "Frigate" sounding as "free" plus "gate" that is as we open a book, a gate is freely opened into a world of imagination, ideas, experiences, feelings, and emotions. In other words, if we find a short poem with a challenging title, we can often analyze the poem skillfully by explaining its diction. When one takes note of the term "traverse", a combination of "traveling", and "verse", one can easily grasp the gist of the poem.

\section{WHAT IS POETRY?}

The word "poetry", in fact comes from a Greek verb which means "to make". At various points in literature history, poetry has been defined as "jigging veins of rhyming mother wits" (Christopher Marlowe); "the spontaneous overflow of powerful feelings" (William Wordsworth); "the opening and closing of a door, leaving those who look through to guess about what is seen during a moment" (Carl Sandburg); and "a momentary stay against confusion" (Robert Frost). The study of poetry produces a natural curiosity about the political, social, moral, and literary trends of a particular time period and is an essential element of a well-rounded liberal arts curriculum.

Short stories, essays, newspaper articles, your college books, and so on, are written in prose. Poetry is usually in verse. Verse is a language with a definite rhythm, or beat. It is usually arranged in columns down the page. Sometimes these columns of lines are divided into units called stanzas. Lines of verse often (but not always) rhyme. Although you could say that poetry is what is written in verse, it is always more than rhythm and rhyme. Poetry, as a great poet said, is the more memorable kind of language.

\section{TYPES OF POETRY}

There are three types of poetry: narrative poetry, dramatic poetry, and lyric poetry.

Narrative poetry is poetry that tells a story. Like a short story, a narrative poem has a plot, characters, a setting, and a theme. Unlike a short story, it is written in verse, language with a definite rhythm, or "beat". In many, but not all narrative poems, the verses rhyme.

Narrative poems, like other kinds of poetry, are often divided into stanzas, or groups of lines that form a unit, rather like paragraphs in prose. The stanzas of a poem usually have the same number of lines and the same rhyme pattern.

Dramatic poetry is poetry in which the speaker is clearly someone other than the poet. Some of the best dramatic poetry consists of dialogue in which more than one character speaks.

Another kind of dramatic poetry is the dramatic monologue: a speech in which a fictional character expresses his or her thoughts and feelings within a developing situation. The word monologue is based on the root mono, meaning "one" - in other words, only one character speaks. Some of the best dramatic monologues come from very plays, such as Shakespeare's, and can stand by themselves as complete poems.

In dramatic poetry, the speaker should not be confused with the author of the poems. Speakers are characters with their own points of view - their own attitudes, backgrounds, and ways of looking at reality. Their thoughts and feelings may be similar to those of the author, or they may be utterly different.

In lyric poetry writers express their thoughts and feelings about a subject in a brief but musical way. The reference of music in this definition is a key point. Of all the different types of poetry, lyrics are most closely related to song. In ancient times lyric poetry was accompanied by the stringed instrument called a lyre - which explains the term lyric. Today such poems are not usually set to music. But they still have a songlike quality.

\section{WORD CHOICE}

What difference does it make whether a poet uses one or another of synonyms such as bond, tie, link, or connection? The answer is that it can matter a great deal. In addition to their denotations, or dictionary meanings, words have different histories. Choosing a word with the wrong connotation for your purposes is the same as singing a song out of tune. For example, would you describe a friendship as a link or connection? The word bond is better able to convey the warm feelings that friends have for each other. 
Mood and tone also depend on a poet's choice of words. Mood is the feeling that a poem creates, while tone is the attitude that a poet takes toward his or her subject and readers. If a poet calls a friendship a connection, he or she may be creating a tone of disapproval toward it. This choice of words may also call up a mood of coldness and a lack of caring. Other factors besides word choice, however, can influence mood and tone.

\section{IMAGERY}

Imagery means a poet's use of words to create mental pictures, or images that communicate experience. An image may appeal to any one of the five senses, though in literature visual images are the most common. When Theodore Roethke describes a meadow mouse as "Wriggling like a miniscule puppy," he is using visual imagery to give you a mental picture of the mouse. When Margaret Walker, in "Memory", speaks of "wind-swept streets of cities / on cold and blustery nights," she is using imagery that appeals to our sense of touch, or physical sensation. Imagery is one of the most important resources poets make use of to capture and express experience.

\section{Figurative language}

Figurative language is a language that is not intended to be interpreted literally. Three common types of figurative language are metaphor, simile, and personification. A simile is a figurative comparison that does not use the word like or as. Personification is the giving of human characteristics to nonhuman things.

\section{Musical Devices}

The term musical devices refers to the various ways poets use the sound of words to enrich their poetry. One of the most frequently used devices is alliteration, the repetition of the same consonant sound, usually at the start of words. When de la Mare writes of the "forest's ferny floor," he is using this device. A similar device is assonance, the repetition of vowel sounds. Poe uses this device in line 3 of "The Bells": "What a world of merriment their melody foretells!" In the same poem, he uses another musical device, onomatopoeia. This is the use of a word whose sound imitates or suggests sound - "How they tinkle, tinkle," he says of the bells.

Alliteration, assonance, and - often - onomatopoeia are forms of the most basic musical device of all: repetition. This device is found not only in particular words or sounds but also in the structure of entire lines of verse. In the passage from Ecclesiastes, all the lines after the first are structured the same way. Each has two pairs of contrasting phrases: "A time to be born, and a time to die; a time to plant and a time to pluck up that which is planted ..." such repetition of similar structured lines is called parallelism. This device is fundamental to the kind of verse Whitman wrote, free verse.

\section{Structure}

The structure of a poem may be described in terms of (1) its stanza form and (2) its meter. A stanza is a unit with a set number of lines. One of the most common stanza forms is the couplet. A couple is a stanza made up of two rhymed lines, as follows:

True ease in writing comes from art, not chance,

As those move easiest who have learned to dance.

Another very common stanza form is the quatrain: a stanza of four lines with any one of several rhyme patterns. Meter is the pattern of accented and unaccented syllables that form the basis of a poem's rhyme. There are a great many different meters in poetry, with many different names. What each one signifies is the number of rhythmic beats (termed "feet") in a line and the arrangement of accented and unaccented syllables in each foot. For example, each line in the couple quoted above has five feet - that is, five beats. A five beat line is called iambic pentameter.

\section{THE SONNET}

The term sonnet derives from the Italian sonetto a 'little sound' or 'song'. Except for the curtal sonnet the ordinary sonnet consists of fourteen lines, usually in iambic pentameters with considerable variations in rhyme scheme. The three basic sonnet forms are: (a) the Petrarchan which consists of an octave rhyming abbaabba and a sestet rhyming cdecde or cdcdcd, or in any combination except a rhyming couplet; (b) the Spenserian of three quatrains and a couplet, rhyming abab, bcbc, cdcd, ee; (c) the Shakesperian, again with three quatrains and a couplet, rhyming abab, cdcd, efef, gg. 
The Italian form is the commonest. The octave develops one thought; there is then a 'turn' or volta, and the sestet grows out of the octave, varies it and completes it.

In the other two forms a different idea is expressed in each quatrain; each grows out of the one preceding it; and the argument, theme and dialectic are concluded, 'tied up' in the binding end couplet.

\section{HAIKU AND CONCRETE POETRY}

Haiku is a Japanese form of poetry. A Haiku consists of three lines of verse the first and third lines have five syllables each, the second line has seven syllables. In this kind of poetry, a detail or two is presented and the reader is left to interpret what they suggest or imply.

Concrete poetry is poetry in which the words are arranged to look like, or something about, the subject being presented.

\section{SONNET SYSTEM}

The basic elements of the sound system in poetry are rhythm, meter, and rhyme. In poetry, rhythm is the arrangement, or pattern, of accented and unaccented syllables - in a word, "the beat". For example, if you read the following lines from Tennyson's poem aloud, you will hear the forceful rhythm of the lines.

$$
\begin{aligned}
& \text { Theirs not to make reply. } \\
& \text { Theirs not to reason why, } \\
& \text { Theirs but to do and die. }
\end{aligned}
$$

Like songs, different poems have different rhythms, usually a poet uses a rhythm that is appropriate to the subject and the poet's feelings about it. When you read a poem, your first concern should be with understanding what the lines mean. Your next concern should be with "catching the beat" and responding to it.

Meter (GK 'measure'): The term refers to the pattern of stressed and unstressed syllables in verse. In English verse, meter is based on stress rather than quantity. A line may have a fixed number of syllables and yet have a varying number of stresses. As a rule meter keeps to a basic pattern, within which there are many variations. A common form of variation is substitution.

In English verse the following meters are the commonest: iambic/; trochaianapaesticuu/; dactylic/UU; spondaic//; paeomic//UUU (first poem).

Coleridge's poem, metrical feet, helps to illustrate the first five of these feet:

Trochee trips from long to short.

From long to ling in solemn sort

Slow spondee stalks strong foot yet ill able

Ever to come up with the dactyl trisyllable.

Iambics march from short to long

With a leap and a bound the swift anapaests throng.

The following terms denote the number of feet per line: monometer-1; dimeter-2; trimester-3; tetrameter-4; pentameter-5; hexameter-6; heptameter-7; octameter-8.

Rhyme has two main functions: (a) it echoes sounds and is thus a source of aesthetic satisfaction. There is pleasure in the sound itself and in the coincidence of sounds; and this pleasure must be associated with the sense music, of rhythm and beat; the pulse sense which is common to all human beings. Part of the pleasure often consists of the surprise that a successful and unexpected rhyme evokes; this is especially true of comic verse where ingenious rhymes make an important contribution to the humor; (b) rhyme assists in the actual structure of verse. It helps to organize the verse, simultaneously opening up and concluding the sense. Thus it is a rhythmical device for intensifying the meaning as well as for 'binding' the verse together. The rhythmical effects are particularly noticeable with head and internal rhyme. Rhyme also helps to make verse easier to remember. Though many poets have not used rhyme - and some have spoken against it - it is unquestionably the commonest and most ancient form of metrical devices. 
A rhyme scheme is a regular pattern of rhyming words in a poem. The rhyme scheme of a poem is indicated by using different letters of the alphabet for each new rhyme. In an abab stanza, for example, line one rhymes with line three and line two rhymes with line four.

$\begin{array}{ll}\text { I wandered lonely as a cloud, } & \text { a } \\ \text { That floats on high o'er vales and hills, } & \text { b } \\ \text { When all at once I saw a crowd } & \text { a } \\ \text { A host, of golden daffodils, } & \text { b } \\ \text { Beside ... } & \end{array}$

\section{Conclusion}

Throughout the paper, definitions of poetry, types of poetry, and its elements were discussed in detail.

\section{REFERENCES}

[1] Cuddon, J.A. (1977). A Dictionary of Literary Terms. Great Britain.

[2] Deedari; R. and Mansouri, M. (2003). Understanding Poetry. Tehran: Rahnama Publications.

[3] Dickinson, E. (1996). The Essential Dickinson. New York.

[4] Marsh, N. (1987).How to Begin Studying English Literature. London.

[5] Nazari Bagha, N. (2003). Poetry in English. Tehran: Islamic Azad University Press.

[6] Ousby, I. (1996). Cambridge Paperback Guide to Literature in English. Cambridge University Press.

[7] Rezai, A.A. (1999). Poetry in English. Tehran: SAMT.

[8] Sokhanvar, J. (1996). The Practice of Literary Terminology. Tehran: SAMT.

\section{AUTHOR's BIOGRAPHY}

I am Saeed Farzane Fard. I was born in Sarab, Iran. I got my PhD in Persian Language and Literature. Now I am the faculty member of Sarab Islamic Azad University. 